\title{
Chromophore Supply Rate-Limits Mammalian Photoreceptor Dark Adaptation
}

\author{
Jin-shan Wang, ${ }^{1}$ Soile Nymark, ${ }^{3,4}$ Rikard Frederiksen, ${ }^{3}$ Maureen E. Estevez, ${ }^{3,5}$ Susan Q. Shen, ${ }^{2}$ Joseph C. Corbo, ${ }^{2}$ \\ M. Carter Cornwall, ${ }^{3}$ and Vladimir J. Kefalov ${ }^{1}$ \\ ${ }^{1}$ Departments of Ophthalmology and Visual Sciences and ${ }^{2}$ Departments of Pathology and Immunology, Washington University School of Medicine, St. \\ Louis, Missouri 63110, ${ }^{3}$ Departments of Physiology and Biophysics, Boston University School of Medicine, Boston, Massachusetts 02118, ${ }^{4}$ Department of \\ Electronics and Communications Engineering, Tampere University of Technology and BioMediTech, FI-33014 Tampere, Finland, and ${ }^{5}$ Department of \\ Neuroscience, Brown University, Providence, Rhode Island 02912
}

Efficient regeneration of visual pigment following its destruction by light is critical for the function of mammalian photoreceptors. Here, we show that misexpression of a subset of cone genes in the $r d 7$ mouse hybrid rods enables them to access the normally cone-specific retina visual cycle. The rapid supply of chromophore by the retina visual cycle dramatically accelerated the mouse rod dark adaptation. At the same time, the competition between rods and cones for retina-derived chromophore slowed cone dark adaptation, indicating that the cone specificity of the retina visual cycle is key for rapid cone dark adaptation. Our findings demonstrate that mammalian photoreceptor dark adaptation is dominated by the supply of chromophore. Misexpression of cone genes in rods may represent a novel approach to treating visual disorders associated with mutations of visual cycle proteins or with reduced retinal pigment epithelium function due to aging.

Key words: dark adaptation; photoreceptors; pigment regeneration; retina; retinol dehydrogenase; visual cycle

\section{Introduction}

Efficient regeneration of visual pigment following its destruction by light is critical for the function of mammalian photoreceptors. Light activation (bleaching) of visual pigment leads to its eventual decay into free opsin and all-trans retinol. Regeneration of the pigment requires recycling of the chromophore in a process known as the visual cycle (Fain et al., 2001; Wang and Kefalov, 2011; Saari, 2012). For rods, all-trans retinol is recycled to 11-cisretinal by the retinal pigment epithelium (RPE). For cones, pigment is regenerated through two mechanisms: the RPE visual cycle and the recently characterized retina visual cycle (Wang and Kefalov, 2009; Wang et al., 2009; Kolesnikov et al., 2011). In this cone-specific pathway, all-trans retinol is isomerized to 11-cisretinol in the retina Müller glia (Kaylor et al., 2013) before it is returned to cones, where it is oxidized to 11-cis-retinal by an unknown enzyme and subsequently used for pigment regeneration (Mata et al., 2002; Parker et al., 2011). The fast pigment regeneration through the retina visual cycle drives the initial

\footnotetext{
Received March 28, 2014; revised June 4, 2014; accepted July 5, 2014.

Author contributions: J.-S.W., S.N., R.F., M.E.E., S.Q.S., J.C.C., M.C.C., and V.J.K. designed research; J.-s.W., S.N., R.F., M.E.E., S.Q.S., J.C.C.,M. C.C., and V.J.K. performed research; J.-S.W., S.N., R.F., M.E.E., S.Q.S., J.C.C., M.C.C., and V.J.K. analyzed data; J.C.C., M.C.C., and V.J.K. wrote the paper.

This work was supported by National Institutes of Health (NIH) grants EY019312 and EY021126 (V.J.K.); EY18826, HG006790, and HG006346 (J.C.C.); EY01157 (M.C.C.); and EY002687 to the Department of Ophthalmology and Visual Sciences at Washington University and by Research to Prevent Blindness Career Development Award (V.J.K.). We thank Janis Lem for the Gnat $1^{-/-}$animals.

The authors declare no competing financial interests.

Correspondence should be addressed to Vladimir J. Kefalov, Ph.D, Department of Ophthalmology and Visual Sciences, Washington University in St. Louis, 660 South Euclid Avenue, St. Louis, Missouri 63110. E-mail: kefalov@wustl.edu.

DOI:10.1523/JNEUROSCI.1245-14.2014

Copyright $\odot 2014$ the authors $\quad 0270-6474 / 14 / 3411212-10 \$ 15.00 / 0$
}

rapid dark adaptation of cones (Kolesnikov et al., 2011) and extends their dynamic range to bright light (Wang and Kefalov, 2009), rendering this pathway essential for the ability of mammalian cones to mediate daytime vision.

A key feature of the retina visual cycle is its cone specificity, which would allow efficient supply of chromophore to cones without competition from rods. This is particularly important for rod-dominant species such as humans and mouse, where the bulk of the chromophore produced by the RPE is consumed by rods. Despite the critical role of rapid pigment regeneration for the function of cones, the molecular mechanisms that make this possible by restricting the retina visual cycle exclusively to cones are not understood. We found a potential way to overcome this problem by using a unique mouse strain, known as retinal degeneration $7(r d 7)$. In this mutant mouse, a spontaneous mutation in the gene encoding the rod transcription factor Nr2e 3 results in the upregulation of a subset of cone genes in its hybrid rods (Chen et al., 2005; Corbo and Cepko, 2005; Peng et al., 2005). We demonstrate that the expression of this subset of cone genes in mouse rods is sufficient to enable them to use 11-cis-retinol for pigment regeneration and to access the retina visual cycle. The rapid supply of chromophore through the retina visual cycle dramatically accelerates dark adaptation of the $r d 7$ hybrid rods, while at the same time competition with rods slows down cone dark adaptation. Our results demonstrate that the dark adaptation of mammalian rods and cones is rate limited by the supply of chromophore. We also show that the cone specificity of the retina visual cycle is key for the rapid dark adaptation of cones. Our results provide a road map to identifying the cellular and molecular mechanisms controlling access to the retina visual cycle and demonstrate the therapeutic potential of misexpressing cone 
genes in rods for visual disorders associated with the pigment epithelium visual cycle.

\section{Materials and Methods}

Animals. To avoid the slow retinal degeneration and decline in visual performance that becomes apparent physiologically after 5 months of age in $r d 7$ mice (Akhmedov et al., 2000), all experiments were conducted in 6- to 12-week-old animals of either sex. The $r d 7$ mice were on a C57BL/6 background (PRID: MGI:3709293), and wild-type C57BL/6 mice were used as controls. For convenience, cone recordings were conducted using mice with deleted $\alpha$-subunit of rod transducin (Gnat ${ }^{-/-}$; Calvert et al., 2000), which prevents rods from generating light responses but does not affect the morphology and function of cones (Nikonov et al., 2006).

Ex vivo electrophysiology. Procedures for single-cell and transretinal electrical recordings have been previously described (Wang and Kefalov, 2010; Kolesnikov and Kefalov, 2012). Briefly, dark-adapted mice were killed, the eyes were removed under infrared light and hemisected, and the retinae were isolated from the pigment epithelium. For single-cell recordings, a retina was chopped into small pieces with a razor blade, placed in a recording chamber, and perfused with $36-38^{\circ} \mathrm{C}$ bicarbonatebuffered Locke solution containing the following (in $\mathrm{mM}$ ): $112 \mathrm{NaCl}, 3.6$ $\mathrm{KCl}, 2.4 \mathrm{MgCl}_{2}, 1.2 \mathrm{CaCl}_{2}, 10 \mathrm{HEPES}, 20 \mathrm{NaHCO}_{3}, 3 \mathrm{Na}_{2}$-succinate, 0.5 $\mathrm{Na}$-glutamate, and 10 glucose, $\mathrm{pH}$ 7.4. Membrane currents were recorded with a suction electrode connected to a conventional patchclamp amplifier. For rods, the outer segment of a single cell protruding from a piece of retina was drawn into the suction electrode. For cones, recordings were done by drawing the cell body of a single photoreceptor into the recording electrode as previously described (Nikonov et al., 2006; Shi et al., 2007). The suction electrode was filled with solution containing the following (in $\mathrm{mm}$ ): $140 \mathrm{NaCl}, 3.6 \mathrm{KCl}, 2.4 \mathrm{MgCl}_{2}, 1.2$ $\mathrm{CaCl}_{2}, 3 \mathrm{HEPES}$, and 10 glucose, $\mathrm{pH}$ 7.4. For transretinal voltage recordings, $1 / 4$ piece of retina was transferred to the recording chamber on filter paper (photoreceptor side up) and perfused with $36-38^{\circ} \mathrm{C}$ bicarbonatebuffered Locke solution containing a mixture of synaptic inhibitors: 2 mM L-aspartate, $\mathrm{pH} 7.4$, and $5 \mu \mathrm{M} \mathrm{L}-(+)$-2-amino-4-phosphonobutyric acid (L-AP4) to block on-bipolar cell signals (Thoreson and Ulphani, 1995; Winkler et al., 1999), NBQX to block AMPA/kainate signals (Yu and Miller, 1995), and $50 \mu \mathrm{M}$ D-AP5 to block NMDA signals (Coleman and Miller, 1988). Barium chloride (10 mM) was added to the solution in the reference electrode space proximate to the ganglion cell layer to suppress glial components of the photoresponse (Green and KapoustaBruneau, 1999). Transretinal recordings were made between an electrode built into the bottom of the chamber and another one positioned above the retina. In both single-cell and transretinal recording conditions, test flashes $(20 \mathrm{~ms}, 500 \mathrm{~nm})$ were delivered from an optical bench. Flash intensity was varied using calibrated neutral density filters. A brief exposure to bright light was used to bleach an estimated $90 \%$ of the visual pigment as previously described (Nymark et al., 2012). Photosensitivity was calculated from the linear region of the intensity-response curve as the ratio of response amplitude and flash intensity. As the photoreceptor sensitivity declines with increasing levels of bleached pigment (Kefalov et al., 2005), we were able to use sensitivity to monitor the pigment regeneration in rods and cones under physiological conditions (Kefalov et al., 2010). Intensity-response data were fit by the Naka-Rushton equation:

$$
\frac{R}{R_{\max }}=\frac{I}{I+I_{o}}
$$

where $R$ is the transient-peak amplitude of response, $R_{\max }$ is maximal response amplitude, $I$ is flash intensity, and $I_{\mathrm{o}}$ is the flash intensity that produces a half-maximal response.

The decline in photoreceptor sensitivity in background light was fit by the Weber-Fechner equation:

$$
\frac{S_{F}}{S_{F}^{D}}=\frac{I_{S}}{I_{S}+I_{B}},
$$

where $S_{F}$ is photoreceptor sensitivity in background light, $S_{F}^{D}$ is photoreceptor sensitivity in darkness, $I_{B}$ (photons $\mu \mathrm{m}^{-2} \mathrm{~s}^{-1}$ ) is the background light intensity, and $I_{S}$ (photons $\mu \mathrm{m}^{-2} \mathrm{~s}^{-1}$ ) is the background light intensity required to reduce sensitivity twofold.

In vivo electrophysiology. In vivo ERG recordings were done as previously described (Kolesnikov et al., 2011). Briefly, mice were anesthetized by subcutaneous injection of a mixture of ketamine $(100 \mathrm{mg} / \mathrm{kg})$ and xylazine $(20 \mathrm{mg} / \mathrm{kg})$, and pupils were dilated with $1 \%$ atropine sulfate. The mouse was placed on a heating pad and maintained at $37^{\circ} \mathrm{C}$. ERG responses were recorded from both eyes with corneal electrodes using an UTAS-E 3000 system (LKC Technologies).

Microspectrophotometry. The level of photopigment in $r d 7$ rods was assessed with a single-beam microspectrophotometer (MSP) that was modified from a similar instrument described previously (MacNichol et al., 1978; Cornwall et al., 1984; Jones et al., 1993). Pigment absorbance was measured as described previously (Nymark et al., 2012).

Dark-adapted spectra were compared with spectra measured following exposure to a $500 \mathrm{~nm}$ light calculated to have bleached $90 \%$ of the pigment. The extent of bleaching was confirmed by comparison of the post- $90 \%$ bleach spectra to spectra measured following exhaustive $(<99 \%)$ bleach. This last measurement was used to calculate the total fraction of bleached photopigment present in rods. Bleaching light was produced by a continuous xenon source, the output of which was passed through a $500 \mathrm{~nm}$ interference filter. Light intensity was calibrated with a silicon photodiode (United Detector Technology). The bleaching light was projected as a circular spot of uniform intensity larger than that of the of the whole retina.

The methods of tissue preparation for microspectrophotometry were largely the same as for single-cell and whole-retina electrical recordings. Retinae of wild-type and $r d 7$ mice were gently isolated from the eyes and the underlying pigment epithelium in L-15 medium (Sigma-Aldrich) under infrared light. One retina was placed on the MSP recording stage for the recordings of dark-adapted spectra. The other retina was exposed to $500 \mathrm{~nm}$ light that was calculated to bleach $90 \%$ of the visual pigment. In certain experiments, the bleached retina was placed in a light-tight container and incubated in a Petri dish in L- 15 medium (with $0.1 \%$ BSA) for at least $2.5 \mathrm{~h}$. In others, the incubation medium also contained $10 \mathrm{~mm}$ $\alpha$-aminoadipic acid (L- $\alpha$-AAA, Sigma), together with $\sim 20 \mu \mathrm{M} \mathrm{11-cis-}$ retinol or 11-cis-retinal dissolved in $0.1 \%$ ethanol (Crouch et al., 2002). In the experiments where the rate of pigment regeneration was measured, the retina was treated with $50 \mu \mathrm{M} 11$-cis-retinal (with $1 \% \mathrm{BSA}$ ) on the microscope stage. Temperature was maintained at $35-37^{\circ} \mathrm{C}$.

For all experiments, data were expressed as mean \pm SEM. Data were analyzed using independent, two-tailed Student's $t$ test, with an accepted significance level of $p<0.05$.

\section{Results}

Physiological properties of dark- and light-adapted $r d 7$ rods In addition to their full complement of rod genes, all $r d 7$ rods express a subset of cone genes (Corbo and Cepko, 2005). This makes the $r d 7$ rods an invaluable tool for understanding the cone specificity of the retina visual cycle. It was previously shown that $r d 7$ rods represent a homogeneous population with hybrid molecular and cellular features (Chen et al., 2005; Corbo and Cepko, 2005). However, it is not known how the extra cone genes affect their physiological properties. Thus, we first sought to determine how the presence of supplemental cone genes affects phototransduction in dark- and light-adapted $r d 7$ rods. We started by characterizing the physiological properties of dark-adapted $r d 7$ rods using single-cell suction recordings and comparing their responses to those of wild-type (C57BL/6) rods. The $r d 7$ rods had normal dark current as measured from saturated responses (compare Fig. 1A, $B$; see also Table 1), indicating healthy photoreceptors with normally-functioning outer segments. This result suggests that the reduced a-wave amplitude of $r d 7$ animals observed in ERG studies is likely due to another cause, possibly the formation of rosettes in the retina (Akhmedov et al., 2000). The sensitivity of $r d 7$ rods was reduced by $\sim 20 \%$ compared with that of wild-type rods (Fig. $1 C$; Table 1 ). In addition, their dim flash 
response kinetics were slightly faster than those of wild-type rods (Fig. 1D, left), with reduced time-to-peak, integration time, and recovery time constant (Table 1). This acceleration persisted throughout the rod's dynamic range and could be observed in brighter, saturated flash responses as well (Fig. $1 D$, right). In addition, a subtle delay in the late phase of response recovery of $r d 7$ rod responses became apparent with even brighter flash stimulation (Figs. $1 A, B, 2 A, C$ ). The reduced sensitivity and accelerated flash response in $r d 7$ rods are reminiscent of cone-like functional properties and are consistent with the acquisition of some cone-like molecular features by the $r d 7$ rods. Overall, however, the light responses of $r d 7$ rods were still quite similar to those of wild-type rods and differed dramatically from those of cones in both sensitivity and kinetics. Notably, the physiological properties of $r d 7$ rods were homogeneous and their light response properties were uniform (compare parameter scatter in Table $1)$, consistent with the single homogeneous population of rod photoreceptors in the $r d 7$ retina (Corbo and Cepko, 2005).

Next, we examined how the expression of a set of cone genes in $r d 7$ hybrid rods affects their ability to adapt to background light. Based on the reduction in their sensitivity to $80 \%$ and the shortening of their response integration time to $78 \%$ of those of wild-type rods, their effective background adaptation would be expected to be reduced to $62 \%$ of that of wild-type rods, resulting in a comparable shift of their functional range to brighter lights. Indeed, we observed a shift in the adaptation curve of $r d 7$ rods compared with controls (Fig. 1F); however, its magnitude was much greater than expected. The background intensity required to reduce sensitivity twofold $\left(I_{S}\right.$ in Eq. 2$)$ increased from $89 \mathrm{R}^{*} \mathrm{~s}^{-1}$ in control rods to $480 \mathrm{R}^{*}$ $\mathrm{s}^{-1}$ in $r d 7$ rods. This greater than fivefold increase in dynamic range indicates that the expression of a set of cone genes in $r d 7$ rods significantly enhances their capacity to adapt to background light.

\section{Dark adaptation of $r d 7$ rods in isolated retina}

The central question of this study was whether the expression of some cone genes by the $r d 7$ rods alters their visual cycle and affects rhodopsin regeneration and dark adaptation. For wildtype rods, the only source of chromophore is the RPE, and removal of the retina from the RPE prevents rhodopsin regeneration (Pepperberg et al., 1978). As a result, exposure of wild-type rods in an isolated retina (in the absence of RPE) to bright bleaching light leads to a permanent loss of their pigment. Physiologically, this pigment loss is manifested by a reduction of adapted.
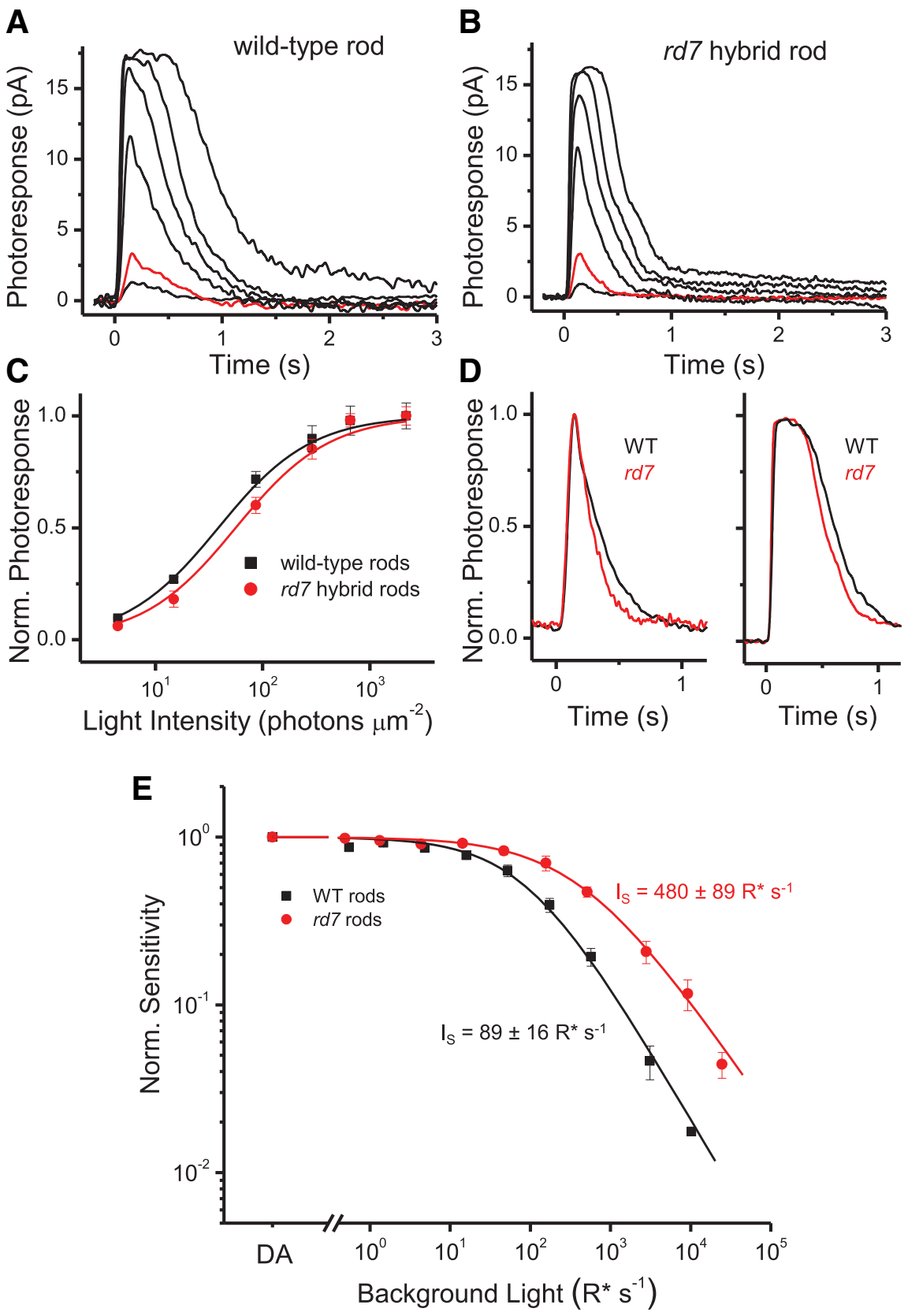

Figure 1. Flash response families from single-cell suction electrode recordings of wild-type $(\boldsymbol{A})$ and $r d 7(\boldsymbol{B})$ rods. Red traces in both parts show responses to 14.8 photon $\mu \mathrm{m}^{-2}$ test flash. C, Intensity-response data from individual wild-type $(n=16)$ and $r d 7$ $(n=8)$ rods fit with Equation 1. Half-saturating flash intensities, $I_{0}$, are given in Table 1. D, Left, Comparison of the kinetics of normalized dim flash responses from wild-type (black) and $r d 7$ (red) rods $\left(n=8\right.$; flash intensity $=14.8$ photon $\mu \mathrm{m}^{-2}$ ). Right, Comparison of the kinetics of saturated flash responses from wild-type (black) and $r d 7$ (red) rods ( $n=8$; flash intensity $=2170$ photon $\left.\mu \mathrm{m}^{-2}\right)$. $\boldsymbol{E}$, background adaptation in wild-type $(n=13)$ and $r d 7(n=6)$ rods. Data are fit with Equation 2. DA, dark

the dark current, acceleration of the flash response, and decreased sensitivity (Fig. 2A). Using single-cell recordings, we found that following a $90 \%$ bleach the dark current of wild-type rods was substantially suppressed (Fig. $2 A$, top) and their sensitivity was reduced by $135 \pm 25$-fold ( $n=12$; Fig. $2 A$, bottom). In contrast, cones in the isolated retina can still regenerate their pigment with chromophore from the Müller cells (Wang et al., 2009) and largely recover their dark current and sensitivity following exposure to bright bleaching light. As cones represent a very small fraction of the photoreceptors in mouse retina $(\sim 3 \%)$, we used Gnat $1^{-/-}$animals, in which rods are unable to generate photo- 
Table 1. Rod response parameters

\begin{tabular}{llllll}
\hline & $I_{D A}(\mathrm{pA})$ & $I_{1 / 2}(\mathrm{~ms})$ & $T_{p}(\mathrm{~ms})$ & $T_{\text {int }}(\mathrm{ms})$ & $\tau_{\text {rec }}$ (ms) \\
\hline WT $(n=16)$ & $16.4 \pm 0.7$ & $55 \pm 3$ & $163 \pm 3$ & $263 \pm 26$ & $231 \pm 26$ \\
$\operatorname{Rd7}(n=12)$ & $14.8 \pm 0.7$ & $70 \pm 10^{*}$ & $145 \pm 2^{a}$ & $204 \pm 15^{*}$ & $151 \pm 15^{*}$
\end{tabular}

Single-cell recording parameters: $I_{D A}$, dark current; $I_{1 / 2}$, flash intensity required to produce half-saturated photoresponse; $T_{p}$, time to peak of the dim flash response; $T_{i n t}$, integration time given by the time integral of the normalized dim flash response; $\tau_{\text {rec, }}$, recovery time constant given by the single exponential fit to the late shut-off phase of the $\operatorname{dim}$ flash response. Data presented are mean $\pm \operatorname{SEM}\left({ }^{*} p<0.05\right)$

responses, to obtain recordings from cones. Following a $90 \%$ bleach, the dark current of control cones from isolated retina largely recovered (Fig. $2 B$, top) and their sensitivity was reduced by only $4.2 \pm 0.7$-fold ( $n=18$; Fig. $2 B$, bottom), indicating substantial cone dark adaptation due to regeneration of cone pigment within the retina. The incomplete recovery of cone sensitivity in isolated retina is consistent with our recent finding that the RPE visual cycle is required for the completion of cone dark adaptation (Kolesnikov et al., 2011). We next examined the level of recovery following pigment bleaching in rods from isolated $r d 7$ retina. Similar to the case in cones and unlike in wild-type rods, the dark current in $r d 7$ rods recovered essentially completely following a $90 \%$ bleach (Fig. $2 C$, top). In addition, their sensitivity recovered to within $16 \pm 3$-fold ( $n=8$; Fig. $2 C$, bottom) from dark-adapted levels. This represents an eightfold (135/16) higher recovery than that observed in wild-type rods and indicates that a substantial fraction of the bleached pigment in $r d 7$ rods was paradoxically regenerated in the isolated retina despite the lack of RPE.

\section{Kinetics of $r d 7$ rod dark adaptation in isolated retina}

The single-cell recordings above clearly demonstrate that the isolated retina is somehow able to promote dark adaptation in $r d 7$ hybrid rods. However, single-cell recordings are not suitable for observing this recovery in real time as the recording electrode appears to disturb the flow of chromophore in and out of photoreceptors (Wang et al., 2009). Thus, we turned to less invasive transretinal recordings (Wang and Kefalov, 2009; Kolesnikov and Kefalov, 2012) to determine the kinetics of dark adaptation in $r d 7$ rods driven by pigment regeneration within the retina. Pharmacological blockage of synaptic transmission (see Materials and Methods for details) allowed us to observe the complete response generated by photoreceptors (a-wave) unobscured by inner retina components, such as the b-wave. Recordings of the voltage response of photoreceptors obtained in this fashion produced waveforms similar to these obtained with single-cell suction electrode recordings. Consistent with our single-cell recordings, we observed a lack of transretinal response recovery in wild-type rods (Fig. 3A), substantial recovery in cones (Fig. 3B), and, notably, a substantial recovery in $r d 7$ rods (Fig. $3 C$ ). Thus, our transretinal recordings confirmed our single-cell results and demonstrated substantial recovery both in response amplitude and sensitivity in the $r d 7$ rods following a bleach.

We next examined the kinetics of this sensitivity recovery. Following a $90 \%$ bleach in wild-type retina, light responses at steady state were desensitized by 122 -fold compared with the responses from the rods that dominate overall sensitivity in darkadapted retina (Fig. 4, dashed line; replotted from Fig. 3A; Wang and Kefalov, 2009). Under these conditions, wild-type rods are substantially and permanently desensitized, and their light responses have sensitivity and amplitude comparable to these of cones (Fig. $3 A, B$ ). In contrast, cones underwent a rapid recovery driven by pigment regeneration via the retina visual cycle (Kolesnikov et al., 2011). The time constant of this cone recovery was
$1.7 \mathrm{~min}$, and the final steady-state cone sensitivity was within twofold of their starting dark-adapted level (Fig. 4; black) despite the absence of RPE. Consistent with our steady-state recordings (Figs. 2C, 3C), we observed robust recovery in the $r d 7$ rods following a bleach in the isolated retina, with a final sensitivity only sixfold below their dark-adapted level but 20-fold higher than in wild-type rods (Fig. 4, red). The time constant of the retina visual cycle-driven dark adaptation in $r d 7$ rods was only $2.4 \mathrm{~min}$. This extremely rapid dark adaptation is consistent with the rapid rate of chromophore recycling through the retina visual cycle (Mata et al., 2002). This retina-driven dark adaptation of $r d 7$ hybrid rods is dramatically faster than the RPE-driven dark adaptation of wild-type rods in vivo (Fig. 7) but still slower than that of cones in isolated retina.

\section{Dark adaptation of $r d 7$ rods in the retina is driven by Müller cells}

We next investigated the mechanism driving the recovery of response amplitude and sensitivity observed in $r d 7$ hybrid rods following a bleach in isolated retina. For cones, pigment regeneration within the retina is driven by chromophore recycled in the Müller glial cells (Wang and Kefalov, 2009). Considering the acquisition of cone-like molecular features by the $r d 7$ rods and their partial dark adaptation in the absence of RPE, we hypothesized that, unlike wild-type rods, these hybrid rods might be able to use chromophore recycled by the retina visual cycle for rhodopsin regeneration. Thus, we investigated how the recovery of $r d 7$ rods is affected by the gliotoxin L- $\alpha$-AAA. Acute treatment with this gliotoxin inhibits the function of Müller cells and thereby blocks the retina visual cycle without affecting the function of photoreceptors (Wang and Kefalov, 2009; Wang et al., 2009). Using transretinal recordings, we examined the responses of $r d 7$ rods following a $90 \%$ bleach in isolated mouse retina that had been pretreated for $2 \mathrm{~h}$ with $10 \mathrm{~mm} \mathrm{~L}-\alpha$-AAA. Unlike the case in control $r d 7$ retina, where substantial rod dark adaptation could be observed (Fig. $3 C$ ), $r d 7$ rods in gliotoxin-treated retina showed no evidence of recovery following the bleach (compare Fig. 5A,B). Thus, pharmacological blockage of the retina visual cycle prevented the dark adaptation of $r d 7$ rods in isolated retina.

\section{Pigment regeneration in $r d 7$ rods in isolated retina}

Our single-cell and transretinal recordings demonstrate that the $r d 7$ hybrid rods undergo substantial dark adaptation in the isolated retina without help from the RPE. This result suggests that these rods can regenerate their rhodopsin with chromophore provided by the retina visual cycle. To demonstrate this directly, and to measure the level of pigment regeneration accompanying this dark adaptation, we performed MSP measurements from patches of photoreceptors in wild-type and $r d 7$ retinae. As rods represent the bulk of photoreceptors in the mouse, the absorption through wild-type retina is dominated by rhodopsin. Thus, the optical density (OD) measured in dark-adapted, wild-type mouse retina peaks at $\sim 500 \mathrm{~nm}$, consistent with the absorption spectrum of mouse rhodopsin (Fig. $6 \mathrm{~A}$, black). Immediately following a $90 \%$ bleach of the photopigment, absorption was reduced $\sim 10$-fold as expected (Fig. $6 A$, blue). In the isolated wildtype retina removed from the RPE, there was no subsequent regeneration of rod pigment even following $3 \mathrm{~h}$ of incubation in darkness (Fig. 6A, red). Consistent with the normal morphology of the outer segments of $r d 7$ rods and the presence of rhodopsin there, their absorption spectra were identical to these of wild-type rods both in dark-adapted conditions (Fig. 6B, black) and immediately following a $90 \%$ bleach (Fig. 6 B, blue). The visual pigment 
A

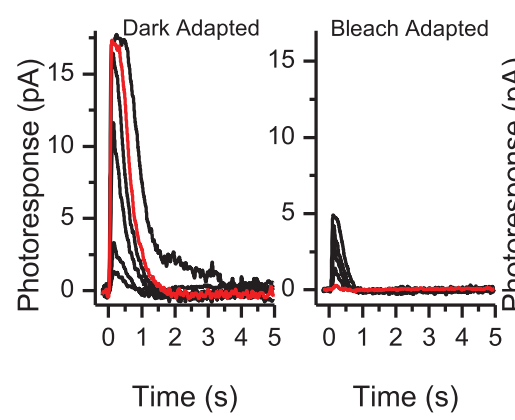

B

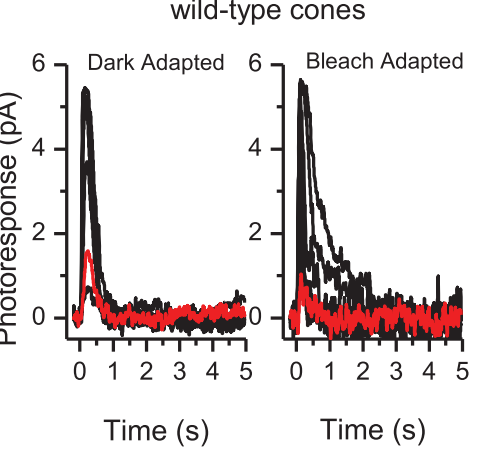

C

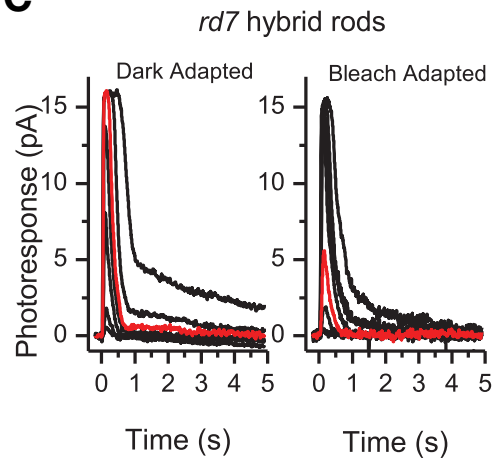

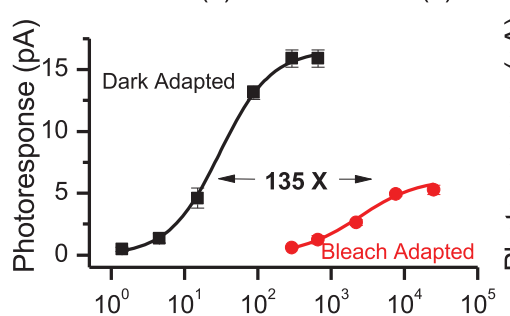

Light Intensity (photons $\mu \mathrm{m}^{-2}$ )

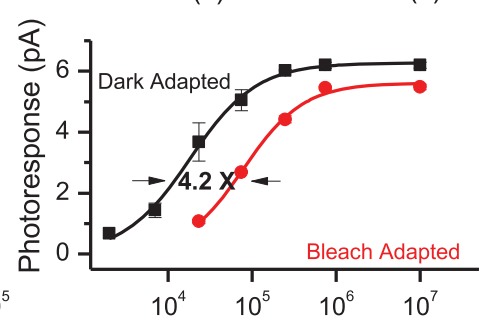

Light Intensity (photons $\mu \mathrm{m}^{-2}$ )

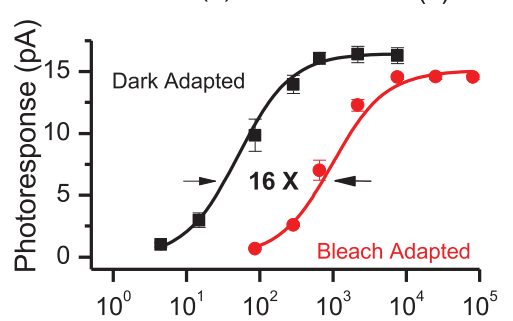

Light Intensity (photons $\mu \mathrm{m}^{-2}$ )

Figure 2. Suction electrode recordings from individual wild-type rods $(\boldsymbol{A})$, cones $(\boldsymbol{B})$, and $r d 7 \operatorname{rods}(\boldsymbol{C})$. Top, left, Families of flash responses in dark-adapted state. Right, Families of flash responses from photoreceptors bleached at $90 \%$ in isolated retina removed from RPE and then incubated in darkness for $3 \mathrm{~h}$. Red traces indicate flash intensities of 655 photon $\mu \mathrm{m}^{-2}$ for wild-type rods ( $\boldsymbol{A}$ ) and $r d 7 \operatorname{rods}(\boldsymbol{C})$ and 2170 photon $\mu \mathrm{m}^{-2}$ for cones $(\boldsymbol{B})$. Bottom, The corresponding intensity-response data for dark-adapted (black squares) and bleach-adapted (red circles) photoreceptors fit with Equation 1. For wild-type rods $(\boldsymbol{A})$, Sf decreased from $2.07 \pm 0.10 \times 10^{-1} \mathrm{pA} \mathrm{photon}{ }^{-1} \mu \mathrm{m}^{2}(n=16)$ to $1.53 \pm 0.26 \times 10^{-3} \mathrm{pA} \mathrm{photon}^{-1} \mu \mathrm{m}^{2}(n=8)$, reflecting a 135 -fold desensitization induced by the bleach. For cones $(\boldsymbol{B})$, Sf decreased from $7.34 \pm 0.25 \times 10^{-4} \mathrm{pA}$ photon ${ }^{-1} \mathrm{um}^{2}(n=8)$ to $1.75 \pm 0.21 \times 10^{-4} \mathrm{pA} \mathrm{photon}{ }^{-1}$ um $^{2}(n=8)$, reflecting a 4.2 -fold desensitization induced by the bleach. For $r$ d $\mathrm{rods}(C)$, Sf decreased from $1.84 \pm 0.18 \times 10^{-1} \mathrm{pA} \mathrm{photon}{ }^{-1} \mathrm{um}^{2}(n=6)$ to $1.16 \pm 0.14 \times 10^{-2}$ pA photon ${ }^{-1} \mathrm{um}^{2}(n=6)$, reflecting a 16 -fold desensitization induced by the bleach. Data are shown as mean \pm SEM.

template (Govardovskii et al., 2000) produced an excellent fit $\left(R^{2}\right.$ $=0.99$ ) to the mean dark-adapted spectrum from $r d 7$ retina (Fig. $6 C$ ) with a peak absorption of $499 \mathrm{~nm}$, consistent with rhodopsin. However, after a subsequent $3 \mathrm{~h}$ incubation in darkness, a third of the bleached rhodopsin had regenerated in $r d 7$ rods, whereas it remained at the post-bleach $10 \%$ level in control rods $(44 \pm 3 \%$ and $13 \pm 2 \%$, respectively, $n=3$ for both). As these experiments were done in the absence of RPE to prevent pigment regeneration through the canonical visual cycle, this result demonstrates that the isolated retina can promote pigment regeneration in $r d 7$ rods. To test whether this pigment regeneration is driven by the retina visual cycle, we pretreated the retina with the Müller cell-specific gliotoxin L- $\alpha$-AAA before the MSP measurements. We observed that blocking the retina visual cycle in this way eliminated the regeneration of rod pigment in the isolated $r d 7$ retina (Fig. 6C).

\section{Pigment regeneration and dark adaptation in $r d 7$ rods with} 11-cis-retinol

The putative product of the retina visual cycle is 11-cis-retinol, which has been shown to promote pigment regeneration and dark adaptation selectively in cones but not in rods (Jones et al., 1989; Wang and Kefalov, 2009; Wang et al., 2009). To test whether the $r d 7$ hybrid rods are indeed capable of using the retina visual cycle, we applied exogenous 11-cis-retinol to $r d 7$ rods from a bleached retina, pretreated with gliotoxin, to block the endogenous retina visual cycle. Whereas in wild-type mouse rods such treatment produces no effect (Wang and Kefalov, 2009), the application of 11-cis-retinol in $r d 7$ rods promoted substantial recovery of their response amplitude and sensitivity (Fig. $5 C$ ). The treatment with 11-cis-retinol also resulted in partial regeneration of the pigment in $r d 7$ rods (Fig. 6D). Notably, however, unlike 11-cis-retinal, which produces a complete dark adaptation in both rods and cones (Wang and Kefalov, 2009), the 11-cisretinol-driven recovery in $r d 7$ rods was only partial, both in pigment content and in sensitivity. In contrast, full regeneration in $r d 7$ rods could be achieved with 11-cis-retinal (Fig. 6E). These results clearly indicate that unlike wild-type rods and similar to cones, the $r d 7$ rods are able to oxidize 11-cis-retinol and use it for rhodopsin regeneration. However, it appears that the capacity of $r d 7$ rods to oxidize 11-cis-retinol is limited under our experimental conditions.

\section{Dark adaptation of $r d 7$ rods and cones in vivo}

Rods in the intact eye can require up to $1 \mathrm{~h}$ to completely recover their sensitivity following exposure to bright light (Rushton, 1965; Fig. 7A). Cones, in contrast, recover within 3-5 min (Kolesnikov et al., 2011; Figs. 4, 7A). It is still not known which step of the rod visual cycle is rate limiting for rod dark adaptation, although it is believed that the underlying reaction resides outside photoreceptors (Lamb and Pugh, 2004; Imai et al., 2007). The $r d 7$ mice, with their ability to use chromophore from the fast retina visual cycle, represent a unique system in which to investigate whether chromophore delivery to rods is rate limiting for their dark adaptation. To determine whether the faster chromophore supply by the retina visual cycle will accelerate dark adaptation in $r d 7$ rods over that in wild-type rods, we performed dark adaptation experiments using in vivo ERG recordings. The a-wave sensitivity recovery in wild-type mice was biphasic, with an initial rapid cone-driven component and a subsequent slower roddriven component (Fig. 7A, black). The recovery of rod sensitivity, driven by the canonical RPE visual cycle, in wild-type mice following a $90 \%$ bleach took $\sim 50 \mathrm{~min}$, as expected. Remarkably, $r d 7$ rod dark adaptation driven by the combined action of the $\mathrm{RPE}$ and retina visual cycles following an identical bleach was 
A
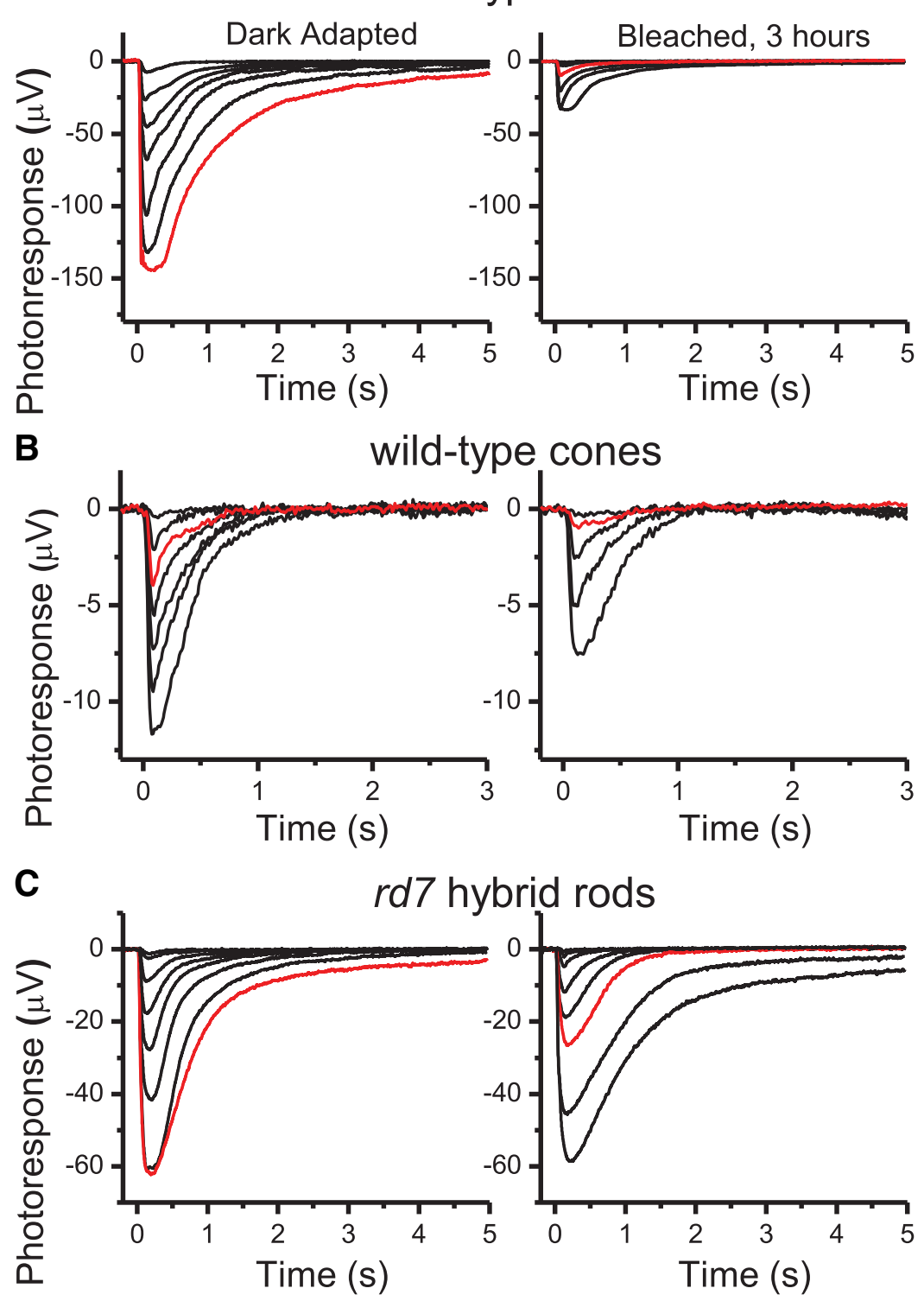

Time (s) wild-type rods
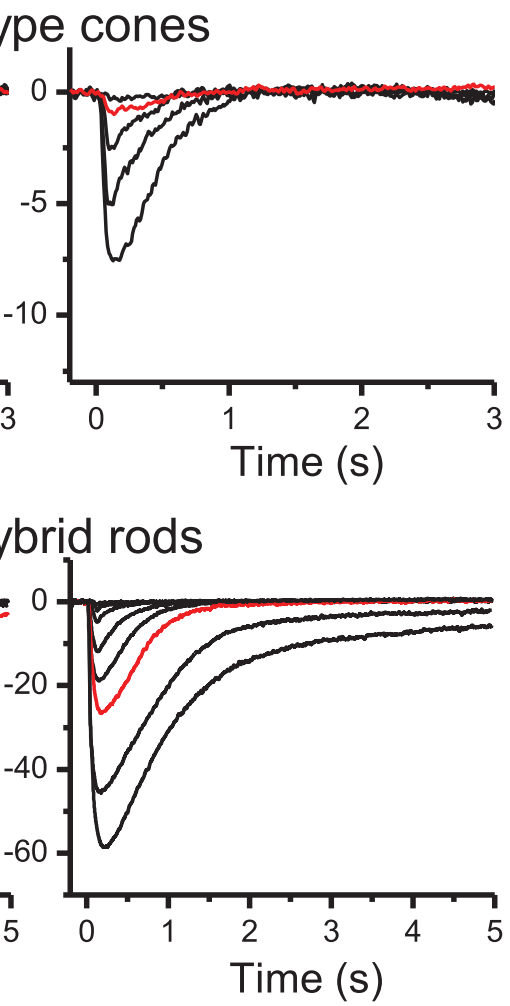

Figure 3. Families of transretinal responses from wild-type rods $(\boldsymbol{A})$, cones $(\boldsymbol{B})$, and $r d 7$ rods $(\boldsymbol{C})$ in dark-adapted retinae (left) and retinae exposed to a $90 \%$ bleach followed by a $3 \mathrm{~h}$ recovery in darkness (right). Red traces represent responses to test flashes of 2170 photon $\mu \mathrm{m}^{-2}$ intensity. Flash strengths increased with a step of $\sim 0.5 \mathrm{log}$ units ( $505 \mathrm{~nm}$ light). Photoreceptors faced the stimulating light.

complete within $20 \mathrm{~min}$ (Fig. $7 A$, red). In both cases the recovery was incomplete, most likely due to the use of anesthetic in these experiments. However, the final sensitivity recovery following the bleach was comparable between wild-type and $r d 7$ mice. Thus, accelerating the delivery of recycled chromophore by the inclusion of the retina visual cycle dramatically accelerated $r d 7$ rod dark adaptation in the intact eye.

To rule out changes in the kinetics of rhodopsin decay and regeneration independent of the supply of chromophore, we used MSP to measure directly these parameters. Metarhodopsin III (Meta III; $\lambda_{\max }=472 \mathrm{~nm}$ ) is a key product of rhodopsin bleaching and its production reflects the decay of physiologically active metarhodopsin II (Meta II). We found that both the production and decay of Meta III were unaffected in $r d 7$ rods (Fig. $7 B$ ). Similarly, the regeneration of rhodopsin in bleached rods supplied with $50 \mu \mathrm{M}$ exogenous 11-cis-retinal was also normal in $r d 7$ rods (Fig. 7C). Thus, the dramatic acceleration of rod dark adaptation in $r d 7$ retina could be attributed directly to the ability of $r d 7$ rods to access the retina visual cycle. Our observation that the decay and regeneration of visual pigment in $r d 7$ rods proceed with kinetics identical to those in wild-type rods clearly demonstrates that any expression of cone opsin in these cells is inconsequential and they overwhelmingly express rod opsin.

Finally, the ability of $r d 7$ hybrid rods to use the retina visual cycle also allowed us to determine the functional significance of this cone specificity for the dark adaptation of cones. We found that forcing cones to compete with the $r d 7$ rods for chromophore from the retina visual cycle resulted in delayed cone recovery (Fig. 7A). Thus, the cone specificity of the retina visual cycle provides one mechanism for ensuring the rapid dark adaptation of cones.

\section{Discussion}

Here we demonstrate a powerful and original approach to understanding the molecular mechanism controlling the operation of the RPE and retina visual cycles and their function in maintaining photoreceptor sensitivity. Our study took advantage of the unique features of rods in the $r d 7$ mouse, which express a subset of cone genes due to the functional deletion of the rod-specific transcription factor Nr2e3 (Chen et al., 2005; Corbo and Cepko, 2005; Peng et al., 2005). We used microspectrophotometry and single-cell and whole-retina recordings from $r d 7$ mouse rods to investigate whether they can use the normally cone-specific retina visual cycle for pigment regeneration and dark adaptation. Our results revealed that despite the acquisition of some conelike features, dark-adapted $r d 7$ photoreceptors produce essentially rod-like responses. However, in contrast to wild-type rods and similar to cones, $r d 7$ rods underwent substantial pigment regeneration and dark adaptation in isolated retina that had been removed from the pigment epithelium. This recovery in $r d 7$ rods could be blocked by pharmacologically inhibiting the retina visual cycle, and then restored by exogenous 11-cis-retinol. Notably, the rate of $r d 7$ rod dark adaptation in vivo was substantially faster than that of wild-type rods. Together, these results demonstrate that the expression of a subset of cone genes in the $r d 7$ rods is sufficient to enable them to use 11-cis-retinol for pigment regeneration and to access the retina visual cycle.

\section{Pigment regeneration and dark adaptation in $r d 7$ rods is} driven by the retina visual cycle

Our assertion that the observed pigment regeneration and dark adaptation in the $r d 7$ rods is driven by the retina visual cycle is based on the implicit assumption that contamination from the RPE makes a negligible contribution to their recovery. Three 


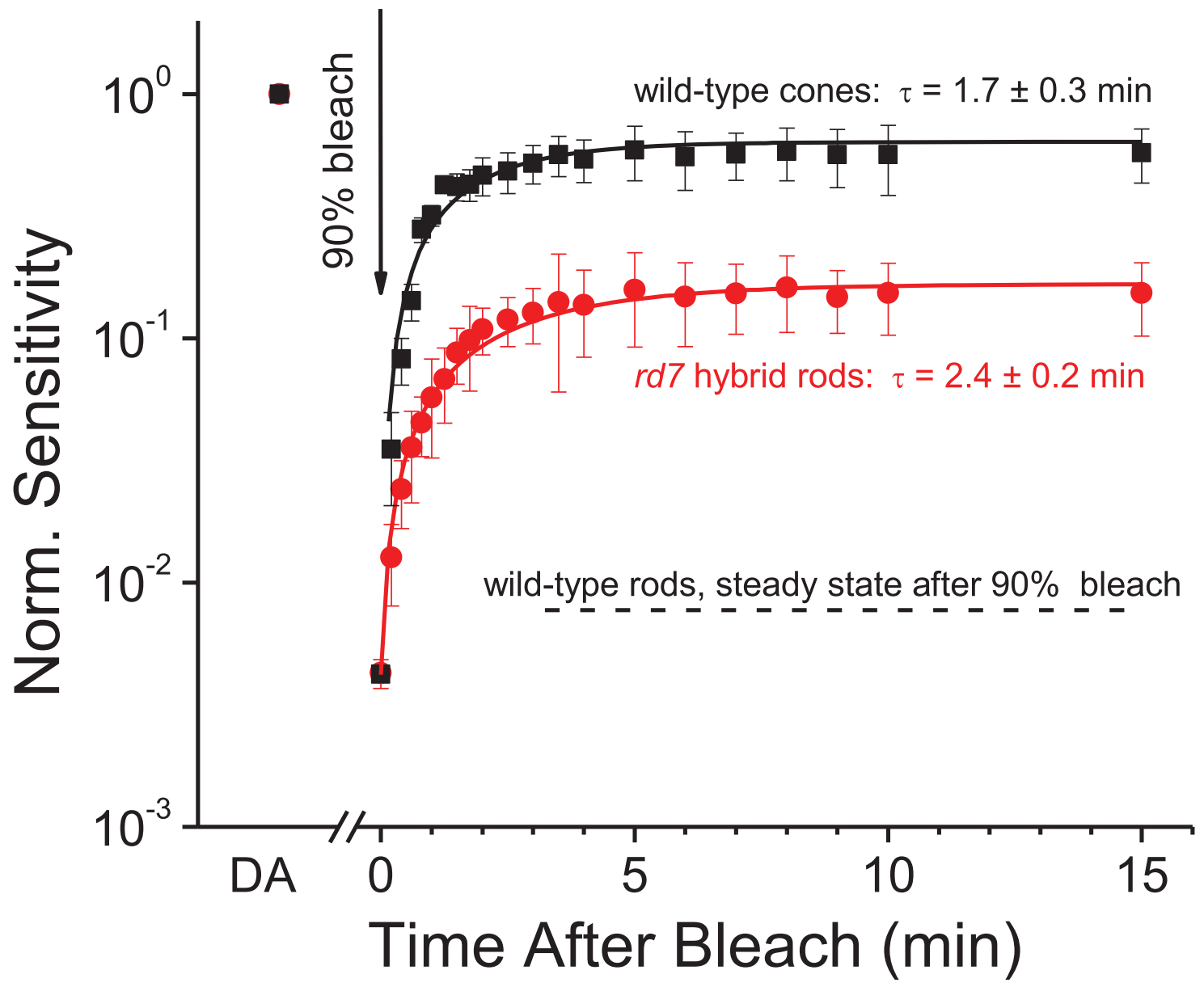

Figure 4. Time course of recovery from a bleach in isolated retina for cones (black squares) and $r d 7$ rods (red circles) determined from transretinal recordings. Sensitivity was normalized to its dark-adapted level before the bleach. The recovery of sensitivity was fit by a single exponential function with a time constant of $1.7 \pm 0.3 \mathrm{~min}$ (black line; $n=10$ ) for cones and $2.4 \pm 0.2$ min (red line; $n=8$ ) for $r d 7$ rods. For comparison, the steady-state level of desensitization in wild-type rods following an identical bleach is also shown (dashed line). Data are shown as mean \pm SEM.

A

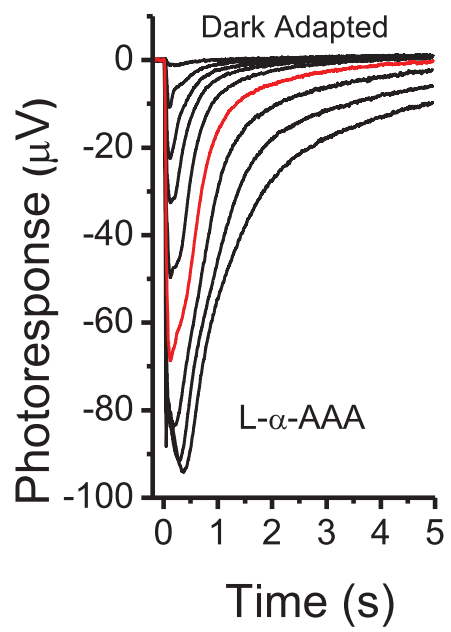

B

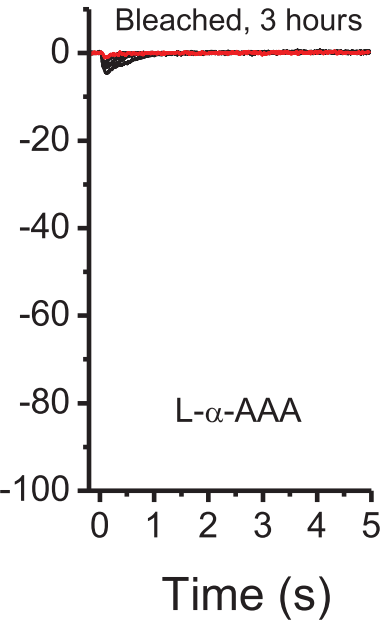

C

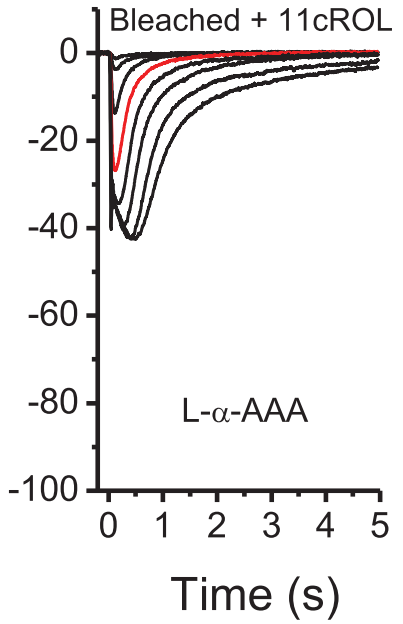

Figure 5. Effect of treatment with the Müller cell-specific gliotoxin L- $\alpha$-AAA on $r d 7$ rod response amplitude and sensitivity following a bleach. Transretinal recordings from $r d 7$ rods in dark-adapted retina $(\boldsymbol{A})$, following a $90 \%$ bleach and $3 \mathrm{~h}$ dark recovery (B), and after a subsequent treatment with $100 \mu \mathrm{M} 11$-cis-retinol (11cROL; $\boldsymbol{C}$. Red traces in all parts correspond to a test flash of 2170 photon $\mu \mathrm{m}^{-2}$ intensity.

arguments support this assumption. First, contamination from RPE in the isolated retina should produce pigment regeneration and dark adaptation not only in $r d 7$ rods but also in wild-type rods. However, our results demonstrate that no such recovery in wild-type rods takes place in the absence of the RPE (Figs. $2 A, 3 A$, $4,6 A$ ). Second, $r d 7$ rod recovery driven by RPE contamination in isolated retina should not be affected by blocking the retina visual cycle. However, we find that selective pharmacological inhibition 
A

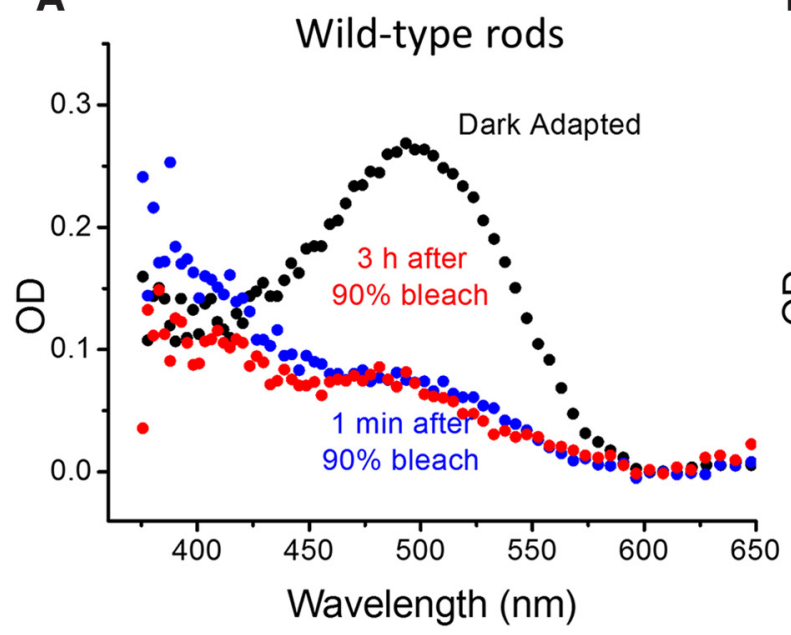

C

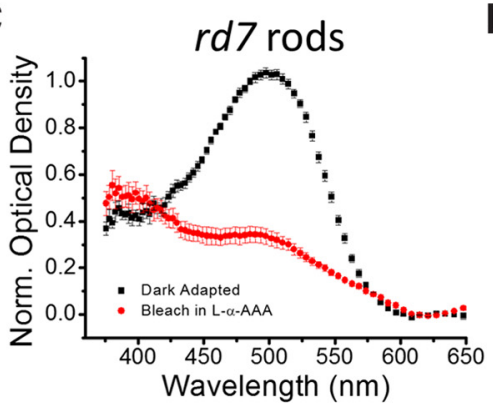

B

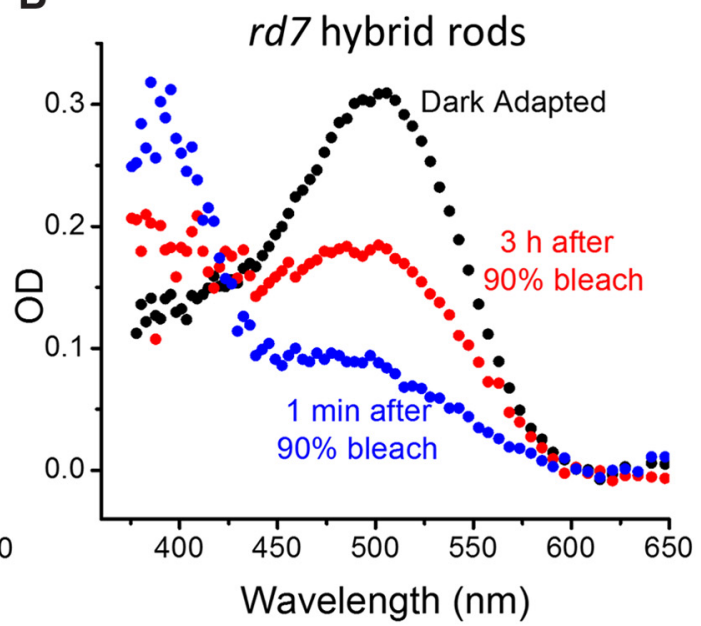

D

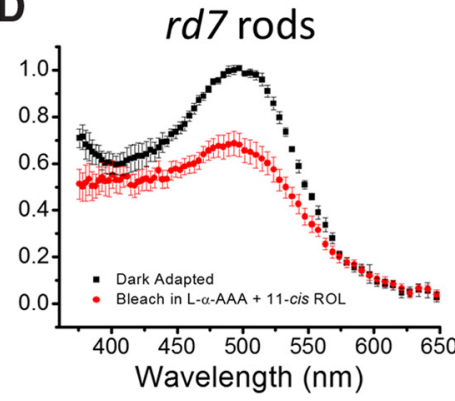

E

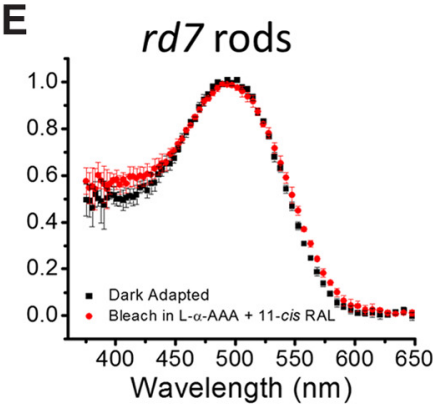

Figure 6. MSP measurements of rhodopsin levels in wild-type and $r d 7$ rods. Absorption spectra of wild-type $(\boldsymbol{A})$ and $r d 7(\boldsymbol{B})$ rod outer segments measured in dark-adapted conditions (black), 1 min after $\sim 90 \%$ bleach (blue), and $3 \mathrm{~h}$ after the $90 \%$ bleach (red). Normalized absorption spectra (mean $\pm \mathrm{SEM}$ ) of $r d 7$ rod outer segments measured in dark-adapted conditions (black squares), after $\sim 90 \%$ bleach and $3 \mathrm{~h}$ incubation (red circles) in L- $\alpha$-AAA $(n=3 ; \boldsymbol{C})$, in L- $\alpha$-AAA with $20 \mu \mathrm{m} 11$-cis-retinol $(n=3 ; \boldsymbol{D})$, and in L- $\alpha$-AAA with $20 \mu \mathrm{M} 11$-cis-retinal $(n=3 ; \boldsymbol{E})$.

of the retina visual cycle with gliotoxin, which does not affect the RPE visual cycle (Wang et al., 2009), completely blocks $r d 7$ pigment regeneration (Fig. 6C) and dark adaptation (Fig. 5B) in isolated retina. Finally, both visual pigment regeneration and sensitivity recovery driven by RPE contamination would be expected to proceed with a time course similar to that of the RPE visual cycle. However, our in vivo ERG recordings demonstrate that $r d 7$ rod dark adaptation is dramatically faster than that of wild-type rods (Fig. 7), an observation consistent with the rapid recycling of chromophore via the retina visual cycle (Mata et al., 2002).

\section{Chromophore delivery rate limits mammalian rod and cone dark adaptation}

One long-standing question in vision research has been the identity of the rate-limiting step for rod and cone dark adaptation. For rods, this process takes tens of minutes (Rushton, 1965; Figure 7) and greatly impairs our ability to see under scotopic conditions for minutes after exposure to bright light. Mutation-induced deficiencies in multiple steps of the visual cycle, from rhodopsin inactivation, to the traffic of chromophore in and out of photoreceptors, and the recycling of chromophore in the RPE (for review, see Travis et al., 2007), all can slow down rod dark adaptation. Here, we demonstrate a substantial acceleration of mammalian rod dark adaptation, indicating that the rate-limiting step for this process has been accelerated. It has been suggested that the rate-limiting step for rod pigment regeneration resides outside photoreceptors (Lamb and Pugh, 2004). Indeed, mutating rhodopsin to accelerate its decay to opsin following photoactiva- tion and its regeneration does not affect the overall rate of pigment recovery during dark adaptation in vivo (Imai et al., 2007). Our finding that the $r d 7$ hybrid rods are able to use the fast retina visual cycle allowed us to test whether supply of chromophore rate limits rod dark adaptation. Our results demonstrate that the retina visual cycle-driven dark adaptation of $r d 7$ rods proceeds surprisingly fast (Fig. 4). Furthermore, we find that overall $r d 7$ rod dark adaptation in vivo, as driven by the combined actions of the retina and RPE visual cycles, occurs 2.5 -fold faster than that of wild-type rods and is complete within only $20 \mathrm{~min}$ (Fig. 7A). These results clearly demonstrate that pigment regeneration and dark adaptation in the $r d 7$ rods proceed substantially faster than in wild-type rods. The normal decay of photoactivated rhodopsin (both Meta II and Meta III) to free opsin (Fig. 7B), and its normal regeneration with exogenous chromophore (Fig. $7 C$ ), indicate that the processing of chromophore in $r d 7$ rods is unaffected. While the expression of yet unidentified auxiliary cone-specific genes might enhance pigment inactivation in $r d 7$ rods, the dramatic acceleration of dark adaptation when chromophore supply is boosted by the fast retina visual cycle indicates that mammalian rod dark adaptation is rate limited by the supply of chromophore. It still remains to be established whether this is also the case in the human retina and whether the recycling of chromophore or its uptake by photoreceptors controls the overall rate of rod dark adaptation.

Our in vivo dark adaptation results from $r d 7$ mice also demonstrate that, in contrast to the accelerated recovery of rods following a bleach, cone dark adaptation is delayed in the $r d 7$ retinae (Fig. 7A). Considering that the mutation in these mice is in the 
rod-specific Nr2e 3 transcription factor, it is unlikely that this delay is caused by altered gene expression or physiological function in the cones. Rather, the slower cone dark adaptation in $r d 7$ retina is most likely due to the competition with the hybrid rods for chromophore recycled by the retina visual cycle. Thus, the cone specificity of the retina visual cycle, which normally excludes rods from using chromophore produced by the Müller cells, is key for the timely regeneration of visual pigment in cones.

Our results also provide insight into the capacity and origin of retinoids that can be supplied by the retina visual cycle. Our MSP measurements demonstrate that the isolated retina can drive the regeneration of $\sim 40 \%$ of rhodopsin in $r d 7$ rods. With total rhodopsin in the mouse retina of $\sim 520$ pmol (Palczewski, 2012), this implies the delivery of $>200$ pmol of chromophore to photoreceptors in a single $r d 7$ mouse retina. This level is too high to be derived from retinoids stored in photoreceptors or the retina (Jin et al., 2009). Thus, the most likely source of substrate for the retina visual cycle is the all-trans retinol released from photoreceptors following a bleach, rather than retinoid storage within the retina.

\section{The $r d 7$ mice offer a unique approach} to understanding the cone specificity of the retina visual cycle

Identifying the cone-specific gene required for the oxidation of 11-cis-retinol would not be trivial in wild-type mice due to the small fraction of cone photoreceptors, making differential expression analysis technically challenging. The cone-like ability of $r d 7$ rods to undergo pigment regeneration driven by the retina visual cycle or by exogenous 11-cis-retinol suggests that these rods express the normally cone-specific enzyme responsible for the oxidation of retinol. Thus, the $r d 7$ rods, expressing only a subset of cone genes, provide a potential avenue for identifying the molecular mechanism that controls access to the retina visual cycle. Notably, in addition to expressing a subset of cone genes, the $r d 7$ rods also acquire some cone-like cellular features. Compared with wild-type rods, the $r d 7$ rods have more abundant euchromatin, larger cell bodies, and juxtanuclear mitochondria while retaining normal outer segments (Corbo and Cepko, 2005). Thus, $r d 7$ rods could also hold the key to understanding the cellular mechanisms that control access to the retina visual cycle.

Finally, as rod pigment regeneration is driven exclusively by the RPE visual cycle, disorders affecting this pathway have devastating effects on rod-mediated vision. Such disorders include retinitis pigmentosa, Leber congenital amaurosis, rod dystrophy, and Stargardt disease (for review, see Travis et al., 2007). Normal

B shown as mean \pm SEM.

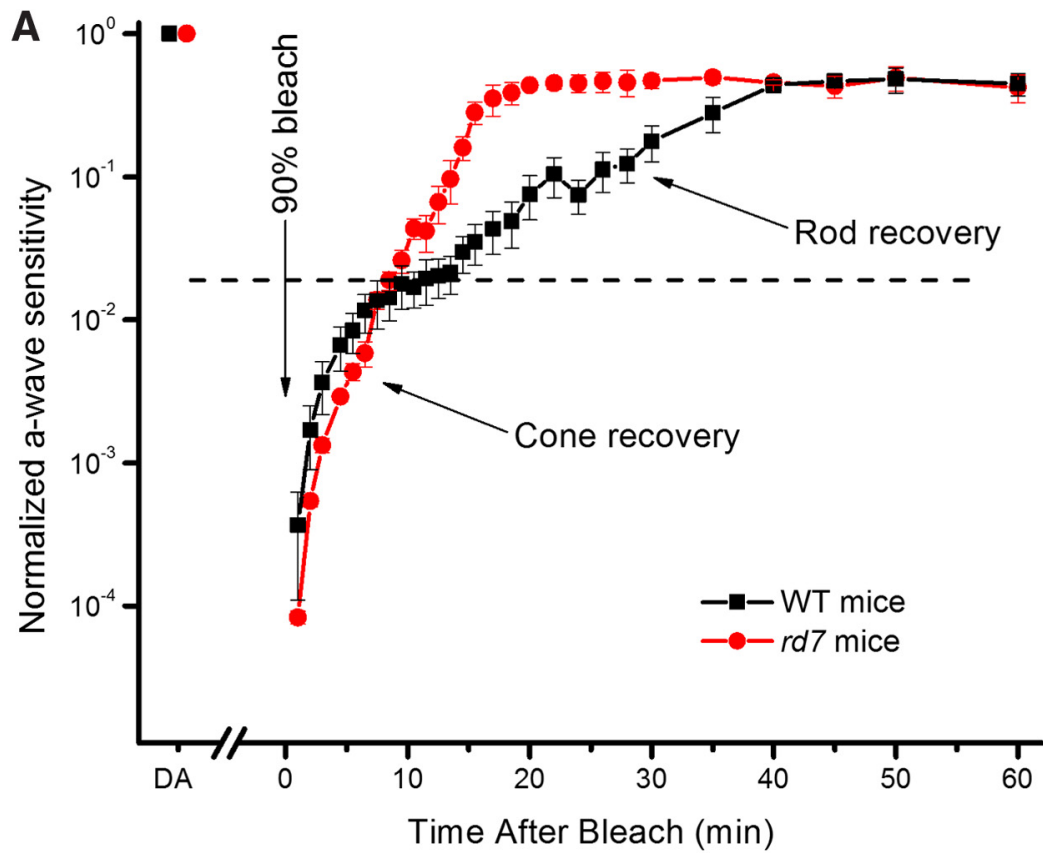

C
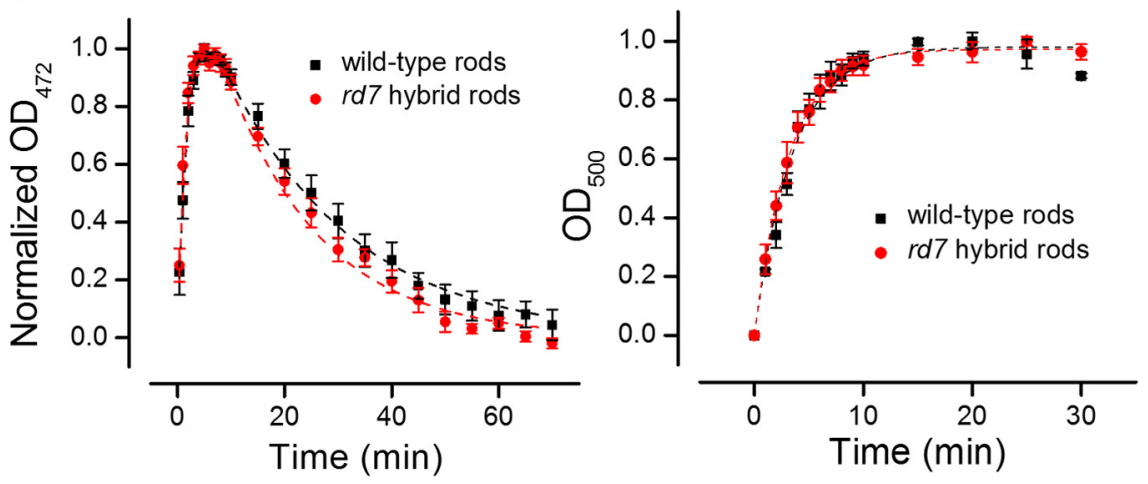

Figure 7. Time course of dark adaptation of wild-type (black squares; $n=6$ ) and $r d 7$ (red circles; $n=6$ ) retinae measured with in vivo ERG recordings $(\boldsymbol{A})$. The a-wave sensitivity was normalized to its dark-adapted level before the bleach. $\boldsymbol{B}$, Production and decay of Met Ill as a function of time after an extensive bleach ( $>90 \%$ ) in wild-type (black squares, $n=9$ ) and $r d 7$ (red circles, $n=$ exponential functions with the time constants $\tau_{1}=2.0, \tau_{2}=23.7 \mathrm{~min}(\mathrm{WT})$, and $\tau_{1}=2.1, \tau_{2}=18.0 \mathrm{~min}$ ( $r d 7$ ). All retinae were $n=7$ ) mice rod photoreceptors. The pigment regeneration was measured by MSP as the change in spectral absorbance at $500 \mathrm{~nm}$ produced time constants of $\tau=3.5 \mathrm{~min}$ (wild-type) and $\tau=3.2 \mathrm{~min}(r d 7)$. All retinae were incubated in L- $\alpha$-AAA for $3 \mathrm{~h}$ prior the start of the experiment. The exogenous treatments were made onstage after the decay of photoproducts was complete. Data are

aging also results in reduced efficiency of the human RPE visual cycle and delayed rod dark adaptation (Jackson et al., 1999,2006). Our study reveals an exciting, novel, and potentially powerful therapeutic approach to such disorders. As our results demonstrate, a genetic manipulation that enables rods to access the normally cone-specific retina visual cycle can compensate for the lack of RPE visual cycle and provide rods with chromophore to sustain rod-mediated vision. Such treatments could prove useful in RPE visual disorders associated with mutations of key visual cycle proteins or with reduced RPE function due to aging. Enabling rods to use the retina visual cycle is indeed achievable in adult mice (Montana et al., 2013). Our results may also advance our understanding of cone visual cycle disorders and drive the 
development of new treatments for cone degenerative diseases such as age-related macular degeneration.

\section{References}

Akhmedov NB, Piriev NI, Chang B, Rapoport AL, Hawes NL, Nishina PM, Nusinowitz S, Heckenlively JR, Roderick TH, Kozak CA, Danciger M, Davisson MT, Farber DB (2000) A deletion in a photoreceptor-specific nuclear receptor mRNA causes retinal degeneration in the rd7 mouse. Proc Natl Acad Sci U S A 97:5551-5556. CrossRef Medline

Calvert PD, Krasnoperova NV, Lyubarsky AL, Isayama T, Nicoló M, Kosaras B, Wong G, Gannon KS, Margolskee RF, Sidman RL, Pugh EN Jr, Makino CL, Lem J (2000) Phototransduction in transgenic mice after targeted deletion of the rod transducin alpha-subunit. Proc Natl Acad Sci U S A 97:13913-13918. CrossRef Medline

Chen J, Rattner A, Nathans J (2005) The rod photoreceptor-specific nuclear receptor Nr2e3 represses transcription of multiple cone-specific genes. J Neurosci 25:118-129. CrossRef Medline

Coleman PA, Miller RF (1988) Do N-methyl-D-aspartate receptors mediate synaptic responses in the mudpuppy retina? J Neurosci 8:4728-4733. Medline

Corbo JC, Cepko CL (2005) A hybrid photoreceptor expressing both rod and cone genes in a mouse model of enhanced S-cone syndrome. PLoS Genet 1:e11. CrossRef Medline

Cornwall, M.C., MacNichol, E.F Jr, Fein, A (1984) Absorptance and spectral sensitivity measurements of rod photoreceptors of the tiger salamander, Ambystoma tigrinum. Vision Res 24:1651-1659. CrossRef Medline

Crouch RK, Kefalov V, Gärtner W, Cornwall MC (2002) Use of retinal analogues for the study of visual pigment function. Methods Enzymol 343: 29-48. CrossRef Medline

Fain GL, Matthews HR, Cornwall MC, Koutalos Y (2001) Adaptation in vertebrate photoreceptors. Physiol Rev 81:117-151. Medline

Govardovskii VI, Fyhrquist N, Reuter T, Kuzmin DG, Donner K (2000) In search of the visual pigment template. Vis Neurosci 17:509-528. CrossRef Medline

Green DG, Kapousta-Bruneau NV (1999) A dissection of the electroretinogram from the isolated rat retina with microelectrodes and drugs. Vis Neurosci 16:727-741. Medline

Imai H, Kefalov V, Sakurai K, Chisaka O, Ueda Y, Onishi A, Morizumi T, Fu Y, Ichikawa K, Nakatani K, Honda Y, Chen J, Yau KW, Shichida Y (2007) Molecular properties of rhodopsin and rod function. J Biol Chem 282: 6677-6684. Medline

Jackson GR, Owsley C, McGwin G Jr (1999) Aging and dark adaptation. Vision Res 39:3975-3982. CrossRef Medline

Jackson GR, McGwin G Jr, Phillips JM, Klein R, Owsley C (2006) Impact of aging and age-related maculopathy on inactivation of the a-wave of the rod-mediated electroretinogram. Vision Res 46:1422-1431. CrossRef Medline

Jin M, Li S, Nusinowitz S, Lloyd M, Hu J, Radu RA, Bok D, Travis GH (2009) The role of interphotoreceptor retinoid-binding protein on the translocation of visual retinoids and function of cone photoreceptors. J Neurosci 29:1486-1495. CrossRef Medline

Jones GJ, Crouch RK, Wiggert B, Cornwall MC, Chader GJ (1989) Retinoid requirements for recovery of sensitivity after visual-pigment bleaching in isolated photoreceptors. Proc Natl Acad Sci U S A 86:9606-9610. CrossRef Medline

Jones GJ, Fein A, MacNichol EF Jr, Cornwall MC (1993) Visual pigment bleaching in isolated salamander retinal cones. Microspectrophotometry and light adaptation. J Gen Physiol 102:483-502. CrossRef Medline

Kaylor JJ, Yuan Q, Cook J, Sarfare S, Makshanoff J, Miu A, Kim A, Kim P, Habib S, Roybal CN, Xu T, Nusinowitz S, Travis GH (2013) Identification of DES1 as a vitamin A isomerase in Muller glial cells of the retina. Nat Chem Biol 9:30-36. CrossRef Medline

Kefalov VJ, Estevez ME, Kono M, Goletz PW, Crouch RK, Cornwall MC, Yau KW (2005) Breaking the covalent bond-a pigment property that contributes to desensitization in cones. Neuron 46:879-890. CrossRef Medline

Kefalov VJ, Cornwall MC, Fain GL (2010) Physiological studies of the inter- action between opsin and chromophore in rod and cone visual pigments. Methods Mol Biol 652:95-114. CrossRef Medline

Kolesnikov AV, Kefalov VJ (2012) Transretinal ERG recordings from mouse retina: rod and cone photoresponses. J Vis Exp pii:3424. CrossRef Medline

Kolesnikov AV, Tang PH, Parker RO, Crouch RK, Kefalov VJ (2011) The mammalian cone visual cycle promotes rapid M/L-cone pigment regeneration independently of the interphotoreceptor retinoid-binding protein. J Neurosci 31:7900-7909. CrossRef Medline

Lamb TD, Pugh EN Jr (2004) Dark adaptation and the retinoid cycle of vision. Prog Retin Eye Res 23:307-380. CrossRef Medline

MacNichol EF Jr, Kunz YW, Levine JS, Hárosi FI, Collins BA (1978) Ellipsosomes: organelles containing a cytochrome-like pigment in the retinal cones of certain fishes. Science 200:549-552. CrossRef Medline

Mata NL, Radu RA, Clemmons RC, Travis GH (2002) Isomerization and oxidation of vitamin A in cone-dominant retinas: a novel pathway for visual-pigment regeneration in daylight. Neuron 36:69-80. CrossRef Medline

Montana CL, Kolesnikov AV, Shen SQ, Myers CA, Kefalov VJ, Corbo JC (2013) Reprogramming of adult rod photoreceptors prevents retinal degeneration. Proc Natl Acad Sci U S A 110:1732-1737. CrossRef Medline

Nikonov SS, Kholodenko R, Lem J, Pugh EN Jr (2006) Physiological features of the S- and M-cone photoreceptors of wild-type mice from singlecell recordings. J Gen Physiol 127:359-374. CrossRef Medline

Nymark S, Frederiksen R, Woodruff ML, Cornwall MC, Fain GL (2012) Bleaching of mouse rods: microspectrophotometry and suction-electrode recording. J Physiol 590:2353-2364. CrossRef Medline

Palczewski K (2012) Chemistry and biology of vision. J Biol Chem 287: 1612-1619. CrossRef Medline

Parker R, Wang JS, Kefalov VJ, Crouch RK (2011) Interphotoreceptor retinoid-binding protein as the physiologically relevant carrier of 11-cisretinol in the cone visual cycle. J Neurosci 31:4714-4719. CrossRef Medline

Peng GH, Ahmad O, Ahmad F, Liu J, Chen S (2005) The photoreceptorspecific nuclear receptor Nr2e3 interacts with Crx and exerts opposing effects on the transcription of rod versus cone genes. Hum Mol Genet 14:747-764. CrossRef Medline

Pepperberg DR, Brown PK, Lurie M, Dowling JE (1978) Visual pigment and photoreceptor sensitivity in the isolated skate retina. J Gen Physiol 71: 369-396. CrossRef Medline

Rushton WA (1965) Visual adaptation. Proc R Soc Lond B Biol Sci 162: 20-46. CrossRef Medline

Saari JC (2012) Vitamin A metabolism in rod and cone visual cycles. Annu Rev Nutr 32:125-145. CrossRef Medline

Shi G, Yau KW, Chen J, Kefalov VJ (2007) Signaling properties of a shortwave cone visual pigment and its role in phototransduction. J Neurosci 27:10084-10093. CrossRef Medline

Thoreson WB, Ulphani JS (1995) Pharmacology of selective and nonselective metabotropic glutamate receptor agonists at L-AP4 receptors in retinal ON bipolar cells. Brain Res 676:93-102. CrossRef Medline

Travis GH, Golczak M, Moise AR, Palczewski K (2007) Diseases caused by defects in the visual cycle: retinoids as potential therapeutic agents. Annu Rev Pharmacol Toxicol 47:469-512. CrossRef Medline

Wang JS, Kefalov VJ (2009) An alternative pathway mediates the mouse and human cone visual cycle. Curr Biol 19:1665-1669. CrossRef Medline

Wang JS, Kefalov VJ (2010) Single-cell suction recordings from mouse cone photoreceptors. J Vis Exp pii:1681. CrossRef Medline

Wang JS, Kefalov VJ (2011) The cone-specific visual cycle. Prog Retin Eye Res 30:115-128. CrossRef Medline

Wang JS, Estevez ME, Cornwall MC, Kefalov VJ (2009) Intra-retinal visual cycle required for rapid and complete cone dark adaptation. Nat Neurosci 12:295-302. CrossRef Medline

Winkler BS, Kapousta-Bruneau N, Arnold MJ, Green DG (1999) Effects of inhibiting glutamine synthetase and blocking glutamate uptake on b-wave generation in the isolated rat retina. Vis Neurosci 16:345-353. Medline

Yu W, Miller RF (1995) NBQX, an improved non-NMDA antagonist studied in retinal ganglion cells. Brain Res 692:190-194. CrossRef Medline 